\title{
An Adherence Trilogy is Essential for Long-Term HAART Success
}

\author{
Rosa Garcia ${ }^{1}$, Robert T. Schooley ${ }^{3}$ and Roberto Badaró ${ }^{1,2}$
}

\author{
Federal University of Bahia ${ }^{1}$; AIDS Reference \\ Center of Salvador/Bahia (CREAIDS $)^{2}$, Salvador, \\ $B A$, Brazil; University of Colorado Health \\ Sciences Center ${ }^{3}$, Denver, Colorado, USA
}

\begin{abstract}
Adherence is the milestone of a successful therapy. Over the last decade several authors have addressed the importance of adherence for optimal results of antiretroviral (ARV) therapy. Many health care systems are investing substantial resources to make available contemporary antiretroviral therapy. Despite the large investment in medications, insufficient investments have been made into an integrated adherence component to maximize the impact of these medications. Adherence, unlike drug therapy, cannot be defined as a single method with a defined prescription or formula. Instead, it is the result of a complex interaction between the patient, a prescribed medication and the health system. Many reports are available analyzing each of these components. We have found that critical elements of adherence include the patient's knowledge about the disease and how medications will help achieve a longer and healthier life, together with the motivation to adapt to a new style of life. A trilogy composed of information, motivation and behavioral skills is essential to achieve the maximum desired level of adherence. We have computerized this trilogy in a software program for self-administration in which each of the three components is provided to the patient as many times as necessary to transmit an understanding of the problem and to help make a rational decision to adhere to the ARV treatment program. In this review we analyze several efforts and techniques to improve adherence to any recommended medication that may interfere with the patient's lifestyle and outline how the adherence trilogy can be best used to optimize the ability of ARV therapy to durably suppress plasma HIV RNA to undetectable levels.
\end{abstract}

Key Words: Adherence, compliance, antiretroviral therapy.

\section{Definition of Adherence}

Adherence is defined by most dictionaries as "to stick, to remain loyal, or to have fidelity" [1]. In medical terminology Blackwell suggested that word "compliance", be replaced by "adherence" in 1975 [2]. Previously, "compliance" was used to define the obedience of the patient to a prescribed medical regimen, This terminology was unsuitable in the view

Received on 15 July 2003; revised 10 October 2003.

Address for correspondence: Dr. Roberto Badaró, MD. Hospital Universitário Prof. Edgard Santos. Rua João das Botas, s/n, Canela, Zip code: 40110-160 Salvador - Bahia - Brazil.

E-mail: badaro@ufba.br

The Brazilian Journal of Infectious Diseases 2003;7(5):307-314 (C) 2003 by The Brazilian Journal of Infectious Diseases and Contexto Publishing. All rights reserved. of many since it implied passivity on the part of the patient [3]. Since adherence to complex medical regimens requires an active interaction between patients, disease, treatment, medical care and outcome it was felt that terminology that implies a more active role for the patient was preferable. Although the World Health Organization proposed to use the term "observance", this was abandoned because, similar to compliance, it also fails to emphasize the wish of the patient to be treated [4]. The real need for an understandable word, which expresses the true interaction between the patient, his disease, treatment and outcome emerged when the HIV/AIDS epidemic evolved to require combination chemotherapy [5-7]. The understanding of the viral replication rate and the infidelity of its replication not only sped up drug discovery, but also became the paradigm of the patient's 
treatment response [8]. Today, doctors, health care workers, even most patients, talk about viral load and its relationship with the success of antiretroviral therapy [9]. Thus the definition of successful antiretroviral therapy has become more objective since it simply requires looking at viral load responses of the patients who are on a recommended ARV treatment [10].

Several reports have emphasized that nonadherence is the main cause for the failure of ARV therapy [11-13]. The unforgiving nature of the virus requires that levels of adherence $(>95 \%)$ be higher and more sustained than in most other areas of medicine. The linear relationship between numbers of daily pills taken and viral suppression is so rigid that a $5 \%$ difference in the adherence rate significantly decreases the rate of virologic success [14]. Although complete virological suppression is achieved in about $78 \%$ of patients who are $95 \%$ adherent to their regimens, the success rate drops to $45 \%$ if patients are only $90 \%$ adherent [14]. Thus, adherence is a major determinant of the rate of HIV virologic suppression in ARV therapy.

What does "adherence" really mean for the patient? In its simplest definition, adherence is judged to be the necessary conditions to achieve therapeutic success. In the 1990's a high daily pill burden was required to administer potent combination regimens. It rapidly became clear that adherence decreases as the number of pills, capsules or tablets increases [15].

Even in best case scenarios the average level of adherence achieved by most patients as, measured by the Medication Event Monitoring System (MEMS) was $74.7 \%$ (14). A number of others studies have found rates between $70 \%$ to $80 \%$ [16-18]. Indeed, full adherence has been defined by many investigators as requiring that patients take $100 \%$ of the prescribed doses each day, at a scheduled dosing time, and in concert with dietary requirement for each the medication in the combination therapy [19]. If we stick to this definition a patient's adherence to a recommended dose and schedule is inflexible. Other aspects of adherence that might be important, in such settings, are neglected. Achieving optimal adherence requires much more than simply instructing the patient to take the recommended medications. Nowadays an active partnership between health care workers and patients is the most important component to help patients live better with HIV/AIDS [20].

The adherence literature has documented direct associations between poor adherence and the complexity of drug regimens. In addition to the number of different medications in a drug regimen, the number of daily pills, dietary limitations, interference with the patients' daily life [21] and the potential harmful or serious adverse reactions that many patients experience are each associated with ARV treatment failure [15]. Another important aspect of adherence is the patients' perception of the direct benefits of the treatment he is receiving. Patients are easily, self-motivated when the medication produces symptom relief, while occurrence of side effects of medications leads to discontinuation of therapy and acquisition of bad fears of that treatment [22]. Unlike in other therapeutic fields, antimicrobial agents do not tolerate frequent lapses in therapy since resistance mutations often emerge in the presence of suboptimal concentrations of drug [3]. Behavioral scientists working to help patients achieve adherence agree that taking medication, following diet, life style changes do not always match with patients' wishes even though these are required to achieve a long term successful therapy [23].

Definitively, adherence requires a multidisciplinary approach in which pill taking is one, but sometimes not the most important component of a treatment regimen - especially in chronic diseases such as HIV infection. The adherence definition must include three major components: information, motivation and behavioral skills.

Before getting into the details of these components, we must analyze adherence by the anthropological point of view. The patients' idea of disease varies according to his cultural background. Some patients perceive the treatment of a disease as punishment [24]. In the imagination of the patient interacting with a physician can facilitate adherence to treatment, but can also work in the reverse if in his culture, as may be the case in developing countries, the physician is an incomprehensive creature [25]. Frequently, a patient's religious beliefs 
will strongly influence a decision to accept a specific treatment. In such cases the best relationship with a physician emerges if the doctor comes from his community and shares with him an acceptable spiritual reason for the treatment provided One approach that might be successful would be to tell the patient that God punished his sins with a disease, but will forgive him, if he accepts the prescribed treatment.

\section{Components of the Adherence Trilogy}

Information. In this trilogy of the components of adherence, information precedes any other procedure. Patients must know about the disease including the cause and implications for his quality of life and the undesirable consequences that will occur if no intervention is provided. In the case of AIDS the knowledge base includes the meanings of viral load and $\mathrm{CD}_{4}$ cell count and how ARV therapy will help him to change the natural course of his disease. Although the digestion of this information by a patient might appear to be very simple to the health care specialist it is often extremely complex for individuals without a background in science. As treatments become more complex even more information must be explained to patient [26].

Motivation. Motivation is the second fundamental in the adherence trilogy. Even though a patient might know about his disease, what HIV does to his immune system and how drugs will help him to control his disease, he will not necessarily adhere to therapy, if he is not motivated. Motivation acts in the threshold limit of psychological disturbance. Depression is the biggest impediment to motivation [27]. Often when a physician feels his patient is not motivated, the real problem is that the patient is depressed. A depressed patient does not feel an enthusiasm or a desire to be treated [28]. Depression may be caused by external factors but it may also be an intrinsic aspect of the patient's individual personality [29]. Depression is common - nearly everyone has experienced a period or moment of low motivation or even a more profound depression. Depressed patients may fail to participate actively in care, may act negatively and may mirror the bad experience that maybe he had with a friend or relative. Individual values are usually structured by his motivation. In ancient times philosophers identified the values external of the people [30].

In the 1890's a new philosophy concluded that the values are inside of each individual. Things have no value; people's wishes are what give value to everything. So, the wishes built the values, motivation transform them to action [31]. In other words, the patients define their values, and if they are treated with such a level of consideration in the hierarchy of his life, then he will be motivated to adhere to treatment.

Behavioral skills. This third component of the trilogy is usually forgotten by health care workers. A prescription always is based on the most appropriate pharmacokinetics of the drugs, but often conflict with the patient's habits. Usually a prescription will require that a patient change his life style. If the patients is able to adjust to this change in life style, the regimen may work temporally. Dietary patterns, job activities and biorhythms are peculiar for most individuals. For many individuals, these issues are considered to be private matters. Treatment must be adapted to the life style of the patient. So, adherence is not just to stick with something. It is far beyond the external attachment. It is an integration with something that from now on will be part of life [32].

\section{Methods for Measuring Adherence}

An array of tools has been employed to assess the level of adherence to medical regimens. We have divided them into two major categories:

a) Patient derived information methods and

b) Methods for independently monitoring drug intake.

Patient-derived information methods. Questionnaires are the most popular and easy method to obtain information about medication adherence. Patient self report or clinicians report, are the two most frequently used tools. 


\section{Patients Medication Adherence Questionnaire} $(P M A Q)$. PMAQ is one of the most widely used questionnaires for assessing adherence in HIV infected patients, especially in clinical trials [33]. Usually, PMAQs are constructed with questions to evaluate sociodemographic behavior, job activities and family history. Another group of questions are related to psychosocial variables, which includes social support, trust in antiretroviral therapy, emotion limitation and psychological functioning. In addition, the most complete questionnaires have questions exploring possible reasons failing to take a dose or doses of medication. In one study Duang et al used 61 items to understand a patient's treatment adherence behavior and its determinants [34]. By providing a quantitative measures of adherence and information on why a patient is or is not adherent, a close relationship was found between patient reports of adherence during the previous 4 days and objectively measured HIV RNA plasma levels [35]. Most studies tend to agree that a majority of patients cannot remember what doses or even full days when doses were missed several weeks prior to a survey [14]. Nevertheless, there are many contradictory data concerning sociodemographic background, social support, alcohol or illicit drugs use [15]. Additional variables are emphasized by other investigators. For example, patients often report bothersome symptoms and side effects associated with ARV therapy result in poor adherence [36,37]. On the other hand, trust in the safety and efficiency of ARV and a fighting "spirit" driven conviction of being able to take the treatment are significantly associated with a higher level of adherence [38,39]. Simple reasons for missing medication such as just forgetting, being busy, being away from home are also frequently associated with poor adherence $[15,39]$.

Other self- reporting questionnaires are also useful or patients may self-report via interview. The major limitation of patient-derived information, however, is that patients usually overestimate their adherence. Walsh and collegues recently described a patient self-reported adherence instrument called the Medication Adherence Self-Report Inventory (MASRI) that uses patient reports of missed doses and a visual analogue scale to approximate overall adherence [40]. Several structured sets of questions on self-reported adherence are useful to measure adherence. However, the recognition of factors which are determinants of non-adherence must systematically be included in self-reported questionnaires; the most common of these factors are related to patientor medication-centered issues (Table 1).

Patient independent drug monitoring techniques. There is no gold standard test for adherence. However, Directly Observed Therapy (DOT) is the most reliable one. Although DOT has been used with success in treating tuberculosis (TB), it is less feasible in HIV disease. Since HIV is a lifetime of therapy and since most drug regimen require two to three daily drug administrations, it is extremely costly to fully apply DOT in clinical practice. In addition, patient and family concerns about confidentiality make it more difficult to employ DOT for prolonged periods in HIV infection [41-43].

The Medication Event Monitoring System (MEMS) has been available for about a decade. This device consists of a microchip housed in a plastic cap that fits on standard medication bottles. The chip records the data and time of each opening and closing of the medication bottle [44]. Several studies have examined the utility of MEMS in measuring adherence [40-43]. Overall self-reported adherence was higher than MEMS [14, 45,46]. However, MEMS adherence was strongly correlated with concurrent viral load [14,4750]. In the paper of Arnsten, the mean self-reported 1-day adherence was 79\% compared to electronic monitoring (MEMS) of 52\%. However, MEMS correlated better with HIV viral load $(\mathrm{r}=.53$ and .60 respectively) [47]. The main reason that MEMS adherence was lower than self-reported adherence was the MEMS system is programmed to register opening the bottle. In the real world, however, most patients removed "pocket doses" of drugs for later administration although the bottle is opened only once. Other measures of adherence that are variably successful are pill counts or pharmacy logs.

Accurate use of the pills count often requires unannounced counts visit because announced pill 
Table 1. Common elements contributing to non-adherence

\section{Patient centered factors}

Misunderstanding of prescribing instructions

Frequent changes to drug regimens

Multiple physicians or health care provider prescribing medications

Limited faith in the effectiveness of the medication or in the care provicder

Inability to read written instructions

Forgetfulness or confusion

Denial of the illness or its significance

Anger about the illness

Apathy

Depression

High stress

Reduction, disappearance or fluctuation in disease symptoms

Concern about taking drugs including fear of becoming addicted

Inability to afford medication

Physical difficulties limiting access to or use of medication

Problems swallowing tablets

Difficulty in opening drug containers

Difficulty in handling small tablets

Difficulty in getting prescriptions filled

Inability to distinguish colors or identifying markings on medications

A history of noncompliance with regimens in the past

Problems with required assistance in the home environment

Concurrent substance abuse,

Limited education about the illness or the need for medication

Limited social or family support

\section{Medication-centered factors}

Adverse real or imagined effects

Complex regimens including multiple drugs or frequent dosing

Unpleasant administration including injection or suppositories

Unpleasant taste or smell,

Drugs that are similar in appearance or with similar names,

Inconvenient or restrictive precautions

Exclusion of alcohol

Exclusion of foodstuffs such as cheese

Specific requirements related to administration in relation to meals 
counts allow patients to "dump" pills and thus can lead to an overestimation of adherence [51]. Pharmacy logs are a simple and practical way to measure adherence, especially in settings such as Brazil were patients are registered in one specific pharmacy. In Brazil, virologic failure occurred more quickly in those patients with gaps in refilling their medication than those with no gaps as indicated by Turner et al. [52-54].

A few studies have used plasma drug levels of ARV to assess adherence in HIV positive patients receiving HAART. However, the short half-lives of the ARV drugs such as zidovudine and protease inhibitors only reflect short-term adherence. Also, poor absorption of a drug leading to decreased plasma levels of that drug might result in a patient been labeled as nonadherent [44]. In a recently published manuscript analyzing untimed ARV drug levels in a population of AIDS patients with advanced disease a significant association was demonstrated between drug level at the first follow up and failure to achieve virologic success during year of therapy. Also in a univariate analysis gender (female) and infection drug users were associated with lower drug levels. The authors concluded that a poor prescription refill record in the pharmacy $(<95 \%)$ and low drug levels of ARV therapy in patients on HAART may reflect incomplete adherence [55].

\section{The CREAIDS Software for Improving Adherence}

We have recently designed a patient-directed, interactive software program that addresses each of the three components of the adherence trilogy. The software is composed of four separate modules. The first module addresses the knowledge base of the patient and includes all necessary information about HIV disease and its treatment. The information is provided to the patient using a very easy to understand combination of words, cartoons and pictures that will help him to understand HIV infection and its consequences. It will include a detailed description of drugs used to treat the infection that will outline how drugs kill the virus, the dose and schedule required and the most common side effect of each drug. In addition, the patient will have the opportunity to ask specific questions that will be answered by pre-prorgammed responses.

The second module will focus on adherence and will familiarize the patient with the most common reasons that patients have discontinued the use of HAART therapy. The patient will learn about common risk factors for non-adherence and will be provided with many illustrations about mistakes that patients make in attempting to follow instructions of their physicians. It will also have a detailed questionnaire for the patient that will help him evaluate his knowledge base and develop the best strategy for him to adhere to his regimen.

The third module is also interactive and will provide information by which the patient will be evaluated as to his motivation according to a quantitative scale. After, a motivation score is determined, the patient will be referred to a psychologist, if this motivation score indicates that specific intervention is indicated. In partnership with the psychologist, the patient will work on specifics problems related to his life and HIV disease. A report will be provided to psychologist that identifies key issues related to each patient. The module also provides each patient with an easy-to-understand report about potential problems as identified by the motivation assessment tool. Each patient will also be provided additional information about how HIV will be part of his life and why actively fighting against HIV will result in a better outcome.

The fourth module is also an evaluation tool in that it tests in an objective fashion what the patient comprehends about the disease and its management from his experience with the first three modules. If he achieves a score of less than $95 \%$ correct or acceptable answers, he will be re- trained with the same program focusing on areas that were identified by the test as being misunderstood before being provided with medicatons. This remedial education will include more hands-on involvement by staff who will directly supervise the computerized training and clarify any residual areas of concern to the patient.

This program is currently under construction and a pilot study with specific parts of this program is under 
evaluation at the AIDS reference center of Bahia CREAIDS. We anticipate that the lack of information about the disease the drugs used to treat it are major contributors to lack of adherence and that this lack of adherence greatly limits the positive impacts of contemporary ARV therapy. If the patients do not understand the complexity of HIV/AIDS their lack of adherence will accelerate the emergence of drug resistant virus. This will in turn complicate management of the illness both in the patient and in the general population of HIV infected individuals, On the other hand, successful patient education about challenges to adherence will improve the patient outcome and will maximize the impact of the massive investment now being made in expanding access to contemporary AIDS therapy to new areas of the world.

\section{References}

1. Spaycar M. Stedman's Medical Dictionary. 26th ed. 1995;28.

2. Blackwell B. Treatment Adherence. Brit J Psychiat 1976;129:513-31.

3. Falk M. Compliance with treatment and the art of medicine. Am J Cardiol 2001;88:668-9.

4. Nobre F, Pierin AMG, Mion Junior D. Adesão ao tratamento. O Grande Desafio da Hipertensão. São Paulo. Lemos Editora. 2001 Cap 1, pp 23-33.

5. Bangsberg D.R., Hecht F.M., Charlebois E.D., et al. Adherence to protease inhibitors, HIV-1 viral load, and development of drug resistance in an indigent population. AIDS 2000; 14:357-66.

6. Cingolani A. Antinori A., Rizzo M.G., et al. Usefulness of monitoring HIV drug resistance and adherence in individuals failing highly active antiretroviral therapy: A randomized study (ARGENTA). AIDS 2002; v16(3):369-79.

7. Press N., Tyndall M.W., Wood E., et al. Virologic and immunologic response, clinical progression, and highly active antiretroviral therapy adherence. JAIDS 2002;31:S112-7.

8. Mellors J.W., Rinaldo C.R. Jr, Gupta P., et al. Prognosis in HIV-1 infection predicted by the quantity of virus in plasma. Science 1996;272:1167-70.

9. Dybul M., Fauci A.S., Bartlett J.G., et al. Guidelines for using antiretroviral agents among HIV-infected adults and adolescents. Ann Int Med. 2002;137(5):381-433.

10. Buss N., Cammack N. Measuring the effectiveness of antiretroviral agents. Antiviral Therapy 2001;6:1-7.
11. Murphy D., Roberts K., Marelich W., Hoffman D. Barriers to antiretroviral adherence among HIV-infected adults. AIDS Patient Care 2000; $14: 47-58$.

12. Lucas G.M., Chaisson R.E., Moore R.D. Highly active antiretroviral therapy in a large urban clinic: Risk factors for virologic failure and adverse drug reactions. Ann Intern Med, 1999;131:81-7.

13. Kastrissios H., Suarez J.R., Hammer S., et al. The extent of non-adherence in a large AIDS clinical trial using plasma dideoxynucleoside concentrations as a marker. AIDS 1998; $12: 2305-11$.

14. Paterson D., Swindells S., Mohr J., et al. Adherence to protease inhibitor therapy and outcome in patients with HIV infection. Ann Intern Med 2000;133:21-30.

15. Chesney M., Ickovics J., Chambers D., et al. Self-reported adherence to antiretroviral medications among participants in HIV clinical trials: The AACTG adherence instruments. AIDS Care 2000;12(3):255-66.

16. Haubrich R., Little S., Currier J., et al. The value of patientreported adherence to antiretroviral therapy in predicting virologic and immunologic response. California Collaborative Treatment Group. AIDS 1999;13:1099-107.

17. Broadhead R., Heackathorn D.D., Altice F.L., et al. increasing drug users' adherence to HIV treatment: Results of a pee-driven intervention feasibility study. Social Science \&Medicine 2002;55:235-46.

18. Howard A.A., Arnsten J.H., Lo Y., et al. A prospective study of adherence and viral load in a large multi-center cohort of HIV-infected women. AIDS 2002;16:2175-182.

19. Tuldrà A., Fumaz C.R., Ferrer M.J., et al. Prospective randomized two-arm controlled study to determine the efficacy of a specific intervention to improve long-term adherence to highly active antiretroviral therapy. JAIDS 2000;25:221-8.

20. Meystre-Agustoni G., Dubois-Arber F., Cochand P., Telenti A. Antiretroviral therapies from the patient's perspective. AIDS Care 2000;12:717-21.

21. Stone V., Strategies for optimizing adherence to highly active antiretroviral therapy: Lessons from research and clinical practice. Clinical Infectious diseases 2001;33:865-72.

22. Holmes W.C., Pace J.L. HIV-seropositive individuals'optimistic beliefs about prognosis and relation to medication and safe sex adherence. Perceptions about HIV-AIDS 2002; 17:677-83.

23. Chesney M.A. Factors affecting adherence to antiretroviral therapy. Clin Infect Dis 2000;30 Suppl 2: S171-6.

24. Greenberg R.N. Overview of patient compliance with medication dosing: A literature review. Clin Ther. 1984;6:592-9.

25. Santos J.Q. Adesão a Tratamentos Médicos. Psiq Prat Méd 2000;33(1):14-6. 
26. Rost K. The influence of patient participation on satisfaction and compliance. Diabetes Educ 1989; 15:134-8.

27. Horenstein M., Moustier C.D., Martineau A. Depression et événements de vie. Paris, France. Ardix Medical 1998:42.

28. Martin P., Ferreri M. Depression et le concept de qualité de vie. Paris, France. Ardix Medical 1997:48.

29. Paykel E. Depressão: uma perspectiva longitudinal. In: Lafer B., Almeida O.P., Fraguas Jr. R., Miguel E.C. Depressão no ciclo de vida. São Paulo, Brasil. Artmed Editora, 2001:266-71.

30. Platon. Oevre Complètes. Paris Pleiade in Tamayo A., Schwartz S.; Estrutura Motivacional dos Valores Humanos. Psic Teor Pesq Brasília 1993, vol 9 No.2:329-48.

31. Tamayo A., Schwartz S. Estrutura Motivacional dos Valores Humanos. Psic Teor Pesq. Brasília 1993;9(2):329-48.

32. Reiter G., Stewart K., Bangsberg D. Elements of success in HIV clinical care: Multiple interventions that promote adherence. Topics in HIV Medicine 2000;8:21-30.

33. Chesney M.A., Morin M., Sherr L. Adherence to HIV combination therapy. Social Science \& Medicine; 2000;50:1599-605.

34. Duong M., Piroth L., Grappin M., et al. Evaluation of the patient medication adherence questionnaire as a tool for selfreported adherence assessment in HIV-infected patients on antiretroviral regimens. HIV Clin Trials 2001;2(2):128-35.

35. Hecht F., Colfax G., Swanson M., et al. Adherence and effectiveness of protease inhibitors in clinical practice. Presented at: Fifth Conference on Retrovirus and Opportunistic Infections; February 1998; Chicago, Abstract 151.

36. Max B., Sherer R. Management of the adverse effects of antiretroviral therapy and medication adherence. Clin Infect Dis. 2000;30Suppl 2:S96-116.

37. Hoggs R.S., Heath K., Bangsberg D., et al. Intermittent use of triple combination therapy is predictive of mortality at baseline and after one year of follow-up. AIDS 2002;16:1051-8.

38. Mostahari F., Riley E., Selwin P., et al. Acceptance and adherence with antiretroviral therapy among HIVinfected women in a correctional facility. J Acquir Immune Defic Syndr Hum Retrovirol 1998; 18:341-8.

39. Gifford A., Bormann J., Shively M., et al. Predictors of self-reported adherence and plasma HIV concentrations in patients on multidrug antiretroviral regimens. J Acquir Immune Defic, Syndr. 2000;23:386-95.

40. Walsh J.C., Mandalia S., Gazzard B.G. Responses to a 1 month self-report on adherence to antiretroviral therapy are consistent with electronic data and virological treatment outcome. AIDS 2002;16:269-77.

41. Chaulk C.P., Kazandijian V.A. Directly observed therapy for treatment completion of pulmonary tuberculosis: Consensus statement of the public health tuberculosis guidelines panel. JAMA 1998;279:943-8.
42. Mitty J.A., Stone V.E., Sands M., et al. directly observed therapy for the treatment of people with human imnunodeficiency virus infection: A word in progress. HIV-AIDS CID 2001;34 (1 April):984-90.

43. Rodriguez-Rosado R., Jimenez-Nacher I., Soriano V., et al. Virological failure and adherence to antiretroviral therapy in HIV-infected patients. AIDS 1998; 12: 1112-3.

44. Cinti S.K. Adherence to antiretroviral in HIV disease. AIDS Read 2000;10(12):709-17.

45. Melbourne K.M., Geletko S.M., Brown S.L., et al. Medication adherence in patients with HIV infection: A comparison of two measurement methods. AIDS Reader 1999;9:329-38.

46. Golin C., Liu H., Hays R., et al. Self-reported adherence to protease inhibitors substantially overestimates an objective measure [abstract 95]. In: Program and abstracts of the $6^{\text {th }}$ Conference on Retroviruses and Opportunistic Infections (Chicago). Alexandria, VA: Foundation for Retrovirology and Human Health 1999:82.

47. Arnsten J.H., Demas P.A., Farzadegan H., et al. Antiretroviral therapy adherence and viral suppression in HIV-infected drug usera: Comparison of self-report and electronic monitoring. Clin Infect Dis 2001;33: 141723.

48. Bangsberg D.R., HechtF.M., Charlebois E.D., et al. Comparing objective measures of adherence to HIV antiretroviral therapy: Electronic medication monitors and ununnounced pill counts AIDS Behav 2001;5: 275-81.

49. Williams A.B. Adherence to highly active antiretroviral therapy. Nurs Clin North Am 1999;34:113-29.

50. Liu H., Golin C.E., Miller L.G., et al. A comparison study of multiple measures of adherence to HIV protease inhibitors. Ann Intern Med 2001;134:968-77.

51. Jones S.G.. Lighting the Future of HIV/AIDS Nursing: 14th Annual Conference of the Association of Nurses in AIDS Care November 11-14, 2001, Minneapolis, Minnesota, USA.

52. Turner B., Newschaffer C., Zhang D., et al. Antiretroviral use and pharmacy-based measurement of adherence in postpartum HIV infected women. Med Care 2000;38: 911-25.

53. Wagner J.H., Justice A.C., Chesney M., et al. Patient- and provider-reported adherence: Toward a clinically useful approach to measuring antiretroviral adherence. J Clin Epideniol 2001;54(Suppl 10):S91-8.

54. Wagner G.J., Rabkin J.G. Measuring medication adherence: Are missed doses reported more accurately that perfect adherence? AIDS Care 2000; $12: 405-8$.

55. Alexander C.S., Asselin J.J., Ting L.S.L., et al. Antiretroviral concentrations in untimed plasma samples predict therapy outcome in a population with advanced disease. JID 2003; $188: 541-8$. 